\title{
The Kinzers Formation (Pennsylvania, USA): the most diverse assemblage of Cambrian Stage 4 radiodonts
}

\begin{tabular}{|r|l|}
\hline Journal: & Geological Magazine \\
\hline Manuscript ID & GEO-18-1993.R1 \\
\hline Manuscript Type: & Original Article \\
\hline Date Submitted by the Author: & n/a \\
\hline Complete List of Authors: & $\begin{array}{l}\text { Pates, Stephen; University of Oxford, Department of Zoology; University of } \\
\text { Lausanne, Institute of Earth Sciences } \\
\text { Daley, Allison; University of Lausanne, Institute of Earth Sciences }\end{array}$ \\
\hline Keywords: & $\begin{array}{l}\text { Cambrian, Kinzers Formation, Anomalocaris, Amplectobelua, Laminacaris, } \\
\text { Tamisiocaris, Radiodonta }\end{array}$ \\
\hline
\end{tabular}

\section{SCHOLARONE ${ }^{\text {m }}$ \\ Manuscripts}


1 The Kinzers Formation (Pennsylvania, USA): the most diverse assemblage of Cambrian

2 Stage 4 radiodonts

3

4 Stephen Pates ${ }^{1,2}$ and Allison C. Daley ${ }^{2}$

5

$6 \quad{ }^{1}$ Department of Zoology, University of Oxford, South Parks Road, Oxford, OX1 3PS, UK.

$7 \quad{ }^{2}$ Institute of Earth Sciences, University of Lausanne, Lausanne $\mathrm{CH}-1015$, Switzerland

8

9 Category: Original article

10 Short title: Kinzers Formation Radiodonta

11

12 Keywords: Cambrian, Kinzers Formation, Anomalocaris, Amplectobelua, Laminacaris,

13 Tamisiocaris, Radiodonta

14

15 Email for corresponding author: stephen.pates@zoo.ox.ac.uk

16 


\section{Abstract}

18

19 Radiodonta, apex Cambrian predators such as Anomalocaris, have been known from the

20 Kinzers Formation (Cambrian Series 2, Stage 4 - Pennsylvania, USA) for nearly 100 years.

21 Work over the last 10 years mainly on radiodont material from the Chengjiang (Cambrian

22 Series 2, Stage 3 - Yunnan, China) and Burgess Shale (Cambrian Series 3, Stage 5 - British

23 Columbia, Canada), has greatly improved our knowledge of the diversity and disparity of

24 radiodonts and their frontal appendages, including the description of new species, genera

25 and families. Previous work identified two species of radiodonts from the Kinzers

26 Formation: Anomalocaris pennsylvanica Resser 1929 and Anomalocaris? cf. pennsylvanica

27 based on isolated frontal appendage material (Briggs 1979). A restudy of Kinzers Formation

28 material shows that only some of the specimens can be confirmed as Anomalocaris

29 pennsy/vanica, and a number of specimens previously attributed to Anomalocaris in fact

30 belong to other more recently discovered radiodont genera Amplectobelua and

31 Tamisiocaris. This reinterpretation makes the Kinzers Formation the most diverse Cambrian

32 Stage 4 Burgess Shale Type Lagerstätten in terms of number of radiodont species. This

33 assemblage includes the youngest known Tamisiocaris and the first from outside Greenland,

34 the only Amplectobelua from Stage 4 and the oldest from Laurentia, two specimens

35 tentatively assigned to the recently described Chengjiang genus Laminacaris, and the

36 endemic Anomalocaris pennsylvanica. The identification of these new radiodont taxa

37 increases the total known diversity of the Kinzers Formation to more than 10 species, and so

38 it should now be considered a Tier 2 Lagerstätten. 


\section{1. Introduction}

42

43 Soft-bodied fossil biota (Konservat-Lagerstätten) such as the famous Chengjiang (Cambrian

44 Series 2, Stage 3) and Burgess Shale (Cambrian Series 3, Stage 5), offer an unrivalled

45 opportunity to study assemblages of animals at snapshots in time. Konservat-Lagerstätten

46 are not distributed evenly through time, but instead are most common in the Cambrian

47 Series 2 and Series 3 (Allison and Briggs 1993; Gaines 2014). The Kinzers Formation

48 (Pennsylvania, USA), has been recognized as a Konservat-Lagerstätten for nearly 100 years,

49 since the discovery of antennae in Olenellus getzi (Dunbar 1925) and the subsequent

50 description of soft-bodied animals (e.g. Resser 1929; Resser and Howell 1938). The

51 exceptionally preserved fauna is confined to the Dyeran (Cambrian Series 2, Stage 4) Fine

52 Pelitic Facies of the Emigsville Member (Skinner 2005). Preservation at different localities

53 varies in iron content, which sometimes overlays and obscures parts of the fossils, owing to

54 differences in the concentration of algae and cyanobacteria of the original sediment

55 (Skinner 2005). The currently known soft-bodied fauna of the Kinzers Formation includes

56 the worms Selkirkia (Conway Morris 1977), Kinzeria crinita and Atalotaenia adela (Garcia-

57 Bellido and Conway Morris 1999), the sponge Hazelia walcotti (Rigby 1987), arthropods such

58 as Serracaris lineata (Briggs 1978), Isoxys (Campbell and Kauffman 1969), Sidneyia

59 (Campbell and Kauffman 1969), Protocaris (Campbell and Kauffman 1969), and Tuzoia

60 (Resser 1929; Campbell and Kauffman 1969; Vannier et al. 2007), and stem-group

61 euarthropod radiodonts (Resser 1929; Briggs 1979), which are the focus of this study. 
64 Since the original description of radiodont material from the Kinzers Formation, including

65 Anomalocaris pennsylvanica (Resser 1929), and subsequent redescription of material

66 following the recognition that Anomalocaris was the appendage of a euarthropod and not

67 the body of a shrimp (Briggs 1979), the number of known species, genera and families of

68 Radiodonta described from other localities has increased substantially. Complete

69 Anomalocaris body fossils were discovered and described (Whittington \& Briggs 1985),

70 Radiodonta were shown to be stem-group euarthropods (Daley et al. 2009) and what began

71 three species described from isolated appendages (Anomalocaris canadensis, $A$.

72 pennsylvanica and 'appendage F' - Briggs 1979) has exploded into a diverse group of apex-

73 predators, many known from complete specimens (Whittington \& Briggs 1985; Chen et al.

74 1994; Hou et al. 1995; Collins 1996; Daley et al. 2009), with diverse feeding strategies

75 representing over 10 genera (Daley et al. 2009; Daley \& Budd 2010; Cong et al. 2014, 2016,

76 2017, 2018; Vinther et al. 2014; Pates et al. 2017; 2018a; Pates \& Daley 2017). Radiodonta

77 fossils have been identified worldwide, from the Great Basin, USA (e.g. Briggs and Mount

78 1982; Lieberman 2003; Briggs et al. 2008; Lerosey-Aubril et al. 2014; Pates et al. 2018b);

79 Iberian Chains, Spain (Pates \& Daley 2017); Holy Cross Mountains, Poland (Daley \& Legg

80 2015); Bohemia, Czech Republic (Chlupáč \& Kordule 2002; Daley et al. 2013a); Hunsruck,

81 Germany (Kühl et al. 2009); as well as more famous sites such as the Burgess Shale, Canada

82 (e.g. Whittington \& Briggs 1985; Collins 1996; Daley and Budd 2010), Chengjiang and Haiku

83 biotas, China (e.g. Chen et al. 1994; Hou et al. 1995; Cong et al. 2014, 2016, 2017, 2018; Guo

84 et al. in press) and Emu Bay Shale, Australia (Nedin 1995; Daley et al. 2013b).

85

86 In this study, the known Radiodonta material from the Kinzers Formation is reassessed in

87 light of the substantial increase in knowledge of these iconic Cambrian animals. Significantly 
88 for this study, two genera, Tamisiocaris Daley \& Peel 2010 and Amplectobelua Hou et al.

89 1995, with frontal appendages superficially similar to Anomalocaris, were described since

90 the last review of the Kinzers Radiodonta by Briggs (1979). Our restudy of the material

91 ascribed to Anomalocaris pennsylvanica and Anomalocaris? cf. pennsy/vanica shows that it

92 in fact belongs to at least four different taxa, and confirms that $A$. pennsylvanica is a distinct

93 species from A. canadensis.

95 2. Identifying Radiodonta using frontal appendages

97 Although rare complete body fossils are known, Radiodonta are most commonly found as

98 isolated elements of the body plan: frontal appendages, mouthparts, carapace elements, or

99 flaps. Of these, isolated frontal appendages are the most common radiodont body element

100 found outside of Tier 1 BSTs, deposits with greater than 100 taxa known, preserved in high

101 fidelity and high abundance (Gaines 2014), and a number of species are known only from

102 frontal appendages, especially from Tier 2 (from 10 to 100 taxa, intermediate fidelity and

103 abundance) and Tier 3 (less than 10 taxa, low fidelity and abundance) BST deposits. Frontal

104 appendages are taxonomically informative, and even partial specimens often provide

105 enough evidence to recognise families, genera or species of radiodonts.

106

107 Radiodont frontal appendages consist of a series of podomeres bearing a diverse

108 morphology of spines and/or endites along their length. Radiodont frontal appendages can

109 be separated into the 'shaft' (sensu Hou et al. 1995, sometimes referred to as the

110 'peduncle') and the 'distal articulated region' (sensu Cong et al. 2018). The shaft normally

111 has more weakly defined boundaries between podomeres and is less sclerotized than the 
112 rest of the appendage, and accordingly it is not always preserved or is only incompletely

113 preserved. It joins the appendage to the body and is joined to the distal articulated region at

114 an angle between $100-180^{\circ}$ on the dorsal surface (Fig. 1a, $\vartheta$ ). The shaft often bears an

115 endite at the distalmost point of the ventral surface (Fig. 1a, shaft endite), and rarely other

116 ventral endites are present on the shaft (e.g. Ramskoeldia platycantha, Cong et al. 2018).

117 The boundary between the shaft and the distal articulated region can be further identified

118 by the presence, in most taxa, of an enlarged or morphologically differentiated ventral

119 endite on the most proximal podomere of the distal articulated region (e.g. Amplectobelua,

120 Lyrarapax) (Fig. 1a, hypertrophied endite). The distal articulated region can itself often be

121 separated into two parts. The proximal part bears ventral endites of the same morphology,

122 differentiating it from the distal part, which often bears either no ventral endites, or

123 reduced and simplified endites, together with dorsal spines (Fig. 1a, dorsal spines, reduced

124 endites).

125

126 The morphology and pattern of ventral endites in particular have been used to identify

127 isolated appendages (Table 1). In Hurdiidae, blade-like ventral endites are the same width

128 (frontal view) as the podomere, and only one ventral endite projects from each podomere

129 (Fig. 1c). Hurdiids always have five of these large identical blade-like ventral endites in the

130 distal articulated region (Fig. 1a, from 1-5). For all other families, the ventral endites are

131 paired on each podomere, and are less than half the width (frontal view) of the podomere

132 to which they attach (Fig. 1b). Families can be differentiated using the relative lengths of

133 ventral endites, the presence of enlarged ventral endites on the post-shaft podomere,

134 and/or the morphology of dorsal spines in the distal articulated region. Anomalocarididae (a

135 clade that includes all species of Anomalocaris except for Anomalocaris briggsi) and 
136 Amplectobeluidae both have enlarged spine-like ventral endites in the distal articulated

137 region, which alternate in length long/short on odd/even podomeres, with a general

138 reduction in the length of ventral endites over the length of the appendage.

139 Amplectobleuidae differ from Anomalocarididae as the ventral endite on the fifth podomere

140 in the distal articulated region is longer than that on the third, and the distal region often

141 bears thickened dorsal spines, in contrast to Anomalocarididae where they are thinner.

142 Tamisiocarididae ('Cetiocaridae' of Vinther et al. 2014), a clade comprising Tamisiocaris

143 borealis and Anomalocaris briggsi (Vinther et al. 2014; Cong et al. 2014; Van Roy et al. 2015)

144 have a pair of elongated and slender ventral endites that have a length at least $1.5 x$ the

145 height (sag) of the podomere to which are attached. The appendage is simple, with the

146 same morphology of ventral endite along the distal articulated region. There is no

147 differentiated post-shaft podomere in Tamisiocaris appendages, although Anomalocaris

148 briggsi does have an enlarged post-shaft ventral endite and an additional endite of similar

149 morphology on the distalmost position of the shaft. There is no alternation of long/short

150 ventral endites in these taxa, with the overall length of ventral endites decreasing along the

151 length of the appendage. Caryosyntrips, Laminacaris, and Lyrarapax have an uncertain

152 placement at family level, but can be distinguished based on features of the frontal

153 appendages. Caryosyntrips appendages taper distally with an approximately triangular

154 outline. Similar to tamisiocaridids, the appendages are simple, with no alternation of

155 long/short ventral endites, and no enlarged endite distal to the shaft. Laminacaris, a

156 recently described monospecific genus from the Chengjiang biota, bears a ventral endite on

157 the most proximal podomere in the distal articulated region similar in morphology to Hurdia

158 ventral endites, but the remainder of the distal articulated region is similar to

159 Anomalocarididae and Amplectobeluidae. Lyrarapax appendages superficially resemble 
160 those of Amplectobeluids, as appendages have an enlarged ventral endite on the post-shaft

161 podomere, and simple ventral endites alternating long/short or present/absent in the distal

162 articulated region. Appendages differ in podomere shape (near square in Lyrarapax and

163 rectangular in Amplectobelua) but the major differences are in the oral cone morphology

164 (tetraradial arrangement of large plates with smaller plates between in Lyrarapax, an

165 association of tuberculate and smooth plates in Amplectobluidae) and gnathobase-like

166 structures present in Amplectobeluidae but not Lyrarapax (Cong et al. 2018; Liu et al. 2018).

167

168 3. Materials and Methods

169

170 Eight specimens of Radiodonta from the Kinzers Formation are known. Material is held at

171 the National Museum of Natural History, Washington D.C., USA (USNM), North Museum,

172 Franklin and Marshall College, Lancaster, Pennsylvania, USA (PA), and Yale Peabody Musem,

173 New Haven, Connecticut, USA (YPM).

174

175 For historical reasons, the part and counterpart of most of the specimens are held at two

176 institutions, the USNM and PA. Some material was not available for study by Briggs (1979),

177 namely the part of the Holotype of Anomalocaris pennsylvanica, and USNM 90827 (Resser

178 and Howell 1938, pl. 13, fig. 5). As another specimen was also labelled USNM 90827 that

179 was available for study by Briggs (1979), there is confusion in the literature about the

180 specimens labelled with this number. The USNM 90827 specimen figured in Resser and

181 Howell (1938, pl. 13, fig. 5) is different to that figured by Briggs (1979, pl. 81, fig. 11, text-fig.

182 34), and Briggs (1979) noted that the specimen figured by Resser and Howell (1938) was

183 different to those in the collection. Both specimens labelled USNM 90827 were available for 
184 this study, but are not part and counterpart. The specimen figured first, by Resser and

185 Howell (1938) retained the number USNM 90827, and the specimen figured second, by

186 Briggs (1979) has been given the altered number USNM 90827A. Both specimens are

187 radiodonts, described herein.

188

189 Specimens were photographed wet and dry under polarized and non-polarized light using a

190 Canon EOS 500D digital SLR Camera with a Canon EF-S 60 mm Macro Lens, controlled for

191 remote shooting using EOS Utility 2. Digital measurements were made using Image J

192 (Schneider et al. 2012). Modern longitude and latitude coordinates were reconstructed to

193 510Ma using GPlates (Scotese 2016). Coordinates were obtained from the literature. Where

194 it was not possible to obtain the exact coordinates of the fossil locality, the nearest town

195 was used in its place.

196

197 4. Systematic Palaeontology

198

199

Total-group EUARTHROPODA Lankester 1904

200

Order RADIODONTA Collins 1996

201

202

?Laminacaris sp.

203

Figure 2

204

v. 1979 Anomalocaris? cf. pennsylvanica; Briggs, pl. 81, figs 9-11, text-figs 33, 34

205 
206 Material: Two partial isolated frontal appendages collected from the Kinzers Formation,

207 Pennsylvania, USA, are known from part and counterpart: USNM 213993, PA 394

208 (counterpart), locality 22L; USNM 90827A, PA 393 (counterpart), locality 12x.

209

210 Description. USNM 213993/PA 394 (Fig. 2a,b) is a partial appendage, with one shaft

211 podomere (Fig. 2b, pd1) and six podomeres in the distal articulated region preserved (Fig.

$2122 b, p d 2-7)$. A pair of thickened recurved ventral endites with distally pointing auxiliary

213 spines is present on the shaft podomere, at the distalmost ventral point (Fig. 2b, pd1).

214 Ventral endites attach to the midpoint of the other podomeres. The ventral endite on the

215 podomere immediately distal to the shaft is curved distally, and approximately the same

216 length and the height (sag) of the podomere, and bears a distally pointing auxiliary spine $2 / 3$

217 of the way down the spine (Fig. 2b, en2). The other ventral endites in the distal articulated

218 region are paired and approximately the height (sag) of the podomere to which they are

219 attached. Distally pointing auxiliary spines are present along the length, and rarely a

220 proximally pointing spine is visible (Fig. 2b, en6). Auxiliary spines point slightly ventrally.

221 Podomeres are tall (sag) rectangles, approximately twice as tall as wide, decreasing in size

222 distally. No dorsal spines are visible.

223

224 USNM 90827A (Fig. 2c,d) preserves 6 rectangular podomeres approximately twice as high

225 (sag) as wide (trans) with ventral endites attached, and traces of two ventral endites that

226 have been prepared out the matrix (Fig. 2d, en9? \& en10?). Just as for USNM213993/PA394,

227 USNM 90827A ventral endites are straight and approximately the same height as the

228 podomere (e.g. Fig. 2 d, en5), and an enlarged endite is present with a single auxiliary spine

$2292 / 3$ of the way along its length at the proximal end, inferred to be pd2 (Fig. $2 d$, en2). One 
230

231

232

233

234

236

237

238

240

241

242

243

244

245

248

250

251

252

253 endite (Fig. $2 d$, en5) is longer than the others. Auxiliary spines project both distally and proximally, with a slight ventral tilt.

Remarks: This taxon is similar to Lamincaris chimera from the Chengjiang biota (Guo et al. in press). This animal, known only from frontal appendages, has straight ventral endites in the distal articulated region with distally pointing auxiliary spines, and enlarged ventral endites on the distalmost point of the shaft and proximal-most post-shaft podomere. The distally pointing auxiliary spines along the length of the endite in Laminacaris chimera from Chengjiang is similar to the arrangement of auxiliary spines in the Kinzers material. The ventral endites are shorter than the height of the podomere to which they attach in both the Chengjiang and Kinzers material, but the alternating long and short endites of Laminacaris chimera is not present in the incompletely preserved Kinzers specimens which are approximately the same length. The enlarged ventral endite in the Kinzers material does not have the distinctive blade-like morphology with a strong similarity to Hurdia ventral endites that is seen in Laminacaris chimera, however it is enlarged relative to the other endites and recurved. This enlarge endite in the Kinzers material bears more similarity to the post-shaft ventral endite of Lyrarapax trilobus or Amplectobelua stephenensis, although it is not as thickened as these two taxa. The endite on the shaft is similar in Laminacaris and this Kinzers taxon, as it bears a single distally facing auxiliary spine approximately two thirds of the distance from the base to the tip. The Kinzers Laminacaris sp. material could also be compared to Anomalocaris briggsi from the Emu Bay Shale, particularly the shape of the podomeres and the possible lack of alternating long/short ventral spines. However, the auxiliary spines point both distally and proximally in A. briggsi, in contrast to the distally pointing spines of the Kinzers specimens, the ventral endites are shorter relative to 
254 podomere height in the Kinzers material than in A. briggsi, and the enlarged ventral endites

255 on the shaft and proximal podomere in the distal articulated region are of a different

256 morphology.

257

258

259

Family ANOMALOCARIDIDAE Raymond 1935

260

Genus ANOMALOCARIS Whiteaves 1892

261

262

Type species. Anomalocaris canadensis Whiteaves 1892 from the Stephen Formation

263 (Cambrian Series 3, Stage 5) of British Columbia, Canada.

264

265

Anomalocaris pennsylvanica Resser 1929

266

Figure 3

267

268

v. 1929 Anomalocaris pennsylvanica; Resser, pl. 5, fig. 5, pl. 79, fig. 5

269

v. 1938 Anomalocaris pennsylvanica; Resser and Howell, pl. 10, fig. 4

270

v. 1979 Anomalocaris pennsy/vanica; Briggs, pl. 79, fig. 5, text-fig. 18, pp. 641

271

272 Holotype. Isolated appendage, Kinzers Formation, Pennsylvania, USA, USNM 80487 (part

273 and counterpart), locality $12 x$.

274 Paratype. Isolated appendage, Kinzers Formation, Pennsylvania, USA, YPM 10425 (part

275 only), locality $12 x$.

276 Other material. Partial isolated appendage, Kinzers Formation, Pennsylvania, USA, USNM

277255611 , locality $22 \mathrm{~L}$. 
279 Diagnosis. Anomalocaris appendage composed of 14 podomeres; one podomere in the

280 shaft wider than tall; 13 podomeres in the distal articulated region taller than wide; all

281 podomeres in the shaft and the distal articulated region bear a pair of ventral endites

282 projecting from the midpoint of the ventral surface; ventral endites are present on pd1-13,

283 lack auxiliary spines, and alternate long/short on even/odd numbered podomeres; ventral

284 endites on proximal podomeres at least as long as the height of the podomere they attach

285 to, and decrease in length relative to podomere height distally; ventral endite of the shaft is

286 not distinct from the ventral endites of the distal articulated region; thin straight dorsal

287 spines project forward from distal dorsal margin of pd9-14; single robust terminal spine. 288

289

Description: Anomalocaris pennsylvanica is known from three specimens: the holotype (part

290 and counterpart) measuring $23 \mathrm{~mm}$ (Fig. 3a,b); a partial small appendage (USNM 255611)

291 (Fig. 3e,f); and a large complete appendage (YPM 10425) measuring 75 mm (Fig. 3c,d).

292 Complete specimens have 14 podomeres, one in the shaft and 13 in the post-shaft region.

293 The presence of a podomere boundary between pd13 and pd14 is confirmed in the

294 holotype by counting the dorsal spines in the distal region, where the podomere boundaries

295 are not well preserved (see Fig. 3b: ds13, ds14). The holotype also potentially shows a

296 second shaft podomere, an approximately square feature preserved as a faint outline,

297 however it joins at an oblique angle to the ventral surface, not the dorsal surface like shaft

298 podomeres in other species (Fig. 3b: ?S). YPM 10425 shows that the shaft bears a large

299 ventral endite at the distal margin (Fig. 3d: en1). YPM 10425 also appears to have a longer

300 ventral endite on pd6 than pd4 (compare Fig. 3d en4 and en6), however the overprint of

301 iron minerals in the rock means that this cannot be confirmed. This is similar to what is seen 
302 in Amplectobleuidae, however the number of podomeres (14) is consistent with

303 Anomalocaris.

304

305 Although the material is limited, the three specimens of different size suggest that the

306 podomeres grew taller relative to the width of podomeres and length of ventral endites

307 through ontogeny, and so larger appendages have smaller ventral endites relative to

308 podomere height. The smallest of the specimens (USNM 255611) has the longest endite to

309 podomere height ratio, at 2:1 at the proximal end. The largest specimen (YPM 10425) has

310 the lowest ratio, at close to $1: 1$ with the ratio in the holotype approximately $1.5: 1$. Similarly

311 the podomere height:width ratio is higher (2.5:1) in YPM 10425 than the holotype (1.5:1).

312 Podomere boundaries are not preserved in USNM 255611.

314 Remarks: Much of the material previously assigned to Anomalocaris pennsylvanica is here

315 reassigned to other radiodont genera (see below). PA 389, PA 395A, and YPM 63295 are

316 removed from Radiodonta altogether because these likely represent partial bodies and

317 appendages of non-radiodont euarthropods.

319 The counterpart to the holotype was not available for study by Briggs (1979) however the

320 interpretation of this specimen, and the description of this species has not changed

321 significantly. Briggs (1979) also noted that larger Anomalocaris pennsylvanica appendages

322 had shorter ventral endites relative to podomere height than smaller appendages of this

323 species. Although the material with the shortest ventral endites is here reassigned to other 324 genera, this observation still holds. 
326 Anomalocaris pennsylvanica Resser 1929 was the second radiodont species to be described,

327 and is only known from isolated frontal appendages. It can be distinguished from

328 Anomalocaris canadensis, the type species, based on the morphology of its ventral endites.

329 In A. pennsy/vanica these are simple, whereas for $A$. canadensis each ventral endite bears

330 two auxiliary spines, creating a trident shape (Briggs 1979). It has been suggested that the

331 lack of auxiliary spines on ventral endites could be taphonomic, in which case $A$.

332 pennsylvanica could be synonymized with $A$. canadensis, however it was retained as a valid

333 taxon based on the limited material available (Briggs 1979; Lieberman 2003; Daley and Peel

334 2010). Anomalocaris pennsy/vanica is here confirmed as a valid taxon. The ventral endites

335 have smooth margins and show no evidence of taphonomically removed auxiliary spines.

336 Furthermore, the three known specimens of $A$. pennsy/vanica show other differences that

337 distinguish it from other Anomalocaris species. It can be differentiated from the most

338 similar species, $A$. canadensis, not only by the lack of auxiliary spines on the ventral endites,

339 but also by the ventral endites being longer relative to podomere height towards the

340 proximal end of the appendage, and by the distal end of the appendage not having

341 differentiated shorter and simplified ventral endites, as is seen in $A$. canadensis. $A$.

342 canadensis also has a reduced ventral endite on the distalmost ventral point of the shaft,

343 whereas $A$. pennsy/vanica has a long ventral endite similar to those of the distal articulated

344 region.

345

346 Anomalocairs pennsylvanica is endemic to the Kinzers Formation, as other specimens

347 attributed to this species from the Pioche Formation (Lieberman 2003) bear auxiliary spines

348 and will be described as a new species of Anomalocaris in an upcoming review of Southern

349 Great Basin material. 
353 Type genus. Tamisiocaris Daley \& Peel 2010

354

355 Diagnosis. Radiodont with a frontal appendage bearing slender blade-like ventral endites

356 longer than the podomere to which they are attached; ventral endites do not alternate 357 long/short.

358

Remarks. The family 'Cetiocaridae' was named by Vinther et al. 2014, however this name is 360 invalid by ICZN conventions (see Van Roy et al. 2015). The family comprises Tamisiocaris and Anomalocaris briggsi, which were recovered together by a phylogeny of radiodonts (Vinther

362 et al. 2014, fig. 3), and subsequently by Cong et al. (2014) and Van Roy et al. (2015).

363

364

Genus TAMISIOCARIS Daley \& Peel 2010

365

Type species. Tamisiocaris borealis Daley \& Peel 2010.

367

368

Diagnosis. Radiodont with paired frontal appendages adjacent to an oval shaped central carapace element; appendage has at least one podomere in the shaft, with 17 podomeres in the distal articulated region separated by a triangular mebrane; shaft podomere is wider

371 (trans) than tall (sag) and bears a straight proximally pointing endite at the distal ventral

372 margin approximately the same length as the height (sag) of the podomere; podomeres in

373 the distal articulated region reduce in height towards the distal end and bear paired slender 
374 ventral endites at least twice the length (sag) of the height (sag) of the podomere; length of

375 ventral endites decreases distally forming a straight line between the distal ends of the

376 ventral endites (emended from Daley and Peel, 2010).

377

378 Remarks. Fine auxiliary spines were not preserved in the holotype of Tamisiocaris, and so

379 not included in the original Diagnosis. They were subsequently recognized in new material

380 described by Vinther et al. (2014), although the diagnosis of genus and species was not

381 updated in that study. As the specimen from the Kinzers Formation assigned to this genus

382 does not have apparent auxiliary spines (see below) the presence of fine auxiliary spines is

383 not included in the diagnosis of this genus.

384

385

Tamisiocaris borealis Daley \& Peel, 2010

386

387

2010 Tamisiocaris borealis; Daley \& Peel, fig. 1

388

2014 Tamisiocaris borealis; Vinther et al., figs 1, 2, extended data figs 1-4, 6, 7

389

390

Holotype. Isolated frontal appendage, Peary Land, central North Greenland, base of the

391

Buen Formation, MGUH 29154, by original designation.

392

Paratypes: Isolated frontal appendages, from same locality as holotype. MGUH 30500

393

(displays articulating triangular membranes); MGUH 30501 (displays fine auxiliary spines),

394

designated herein.

395

Other material: Three other isolated frontal appendages of this species are known, also

396 from same locality as holotype. MGUH $30502-4$. 
398 Diagnosis. Tamisiocaris with an appendage that bears fine auxiliary spines along the length

399 of both proximal and distal surfaces of the ventral endites; auxiliary spines are straight, do

400 not change length along the appendage and are separated vertically by less than the width

401 (trans) of the ventral endite (emended from Daley \& Peel, 2010).

402

403 Remarks. Tamisiocaris borealis was originally described as a radiodont frontal appendage by

404 Daley and Peel (2010). A subsequent study by Vinther et al. (2014) with new material

405 provided new information about the appendage, including the presence of triangular

406 articulating membrane between the podomeres and fine auxiliary spines along the length of

407 the ventral endites. This confirmed the hypothesis that the taxon belongs to Radiodonta,

408 and suggested a sifting/filtering feeding ecology, however Vinther et al. (2014) did not

409 update the Diagnosis of the genus or species, nor designate new paratypes with these new

410 features. This has been done here to allow comparison with the Kinzers Formation material.

411

412

Tamisiocaris aff. borealis

413

Figure 4

414

v. 1938 Anomalocaris pennsylvanica; Resser and Howell, pl. 13, fig. 5

415

v. 1979 Anomalocaris pennsylvanica; Briggs pp. 641

416

417 Material: Partial isolated frontal appendage, Kinzers Formation, Pennsylvania, USA, USNM

41890827, PA 388 (counterpart).

419

420 Description. USNM 90827/PA 388 (Fig. 4) shows a partial appendage of 9 podomeres (Fig.

$4214 b, ? p d 10-$ ?pd18), each bearing a long and slender ventral endite (Fig. 4b, en). The 
422 podomeres are approximately square where boundaries can be discerned (e.g. Fig. 4b,

423 ?pd14) with the ventral endites twice the height (sag) of the podomeres. The podomeres

424 reduce in height towards the distal end, where the shape becomes an elongate rectangle

425 (e.g. Fig. 4b, ?pd18). No auxiliary spines are visible on the ventral endites, and no dorsal

426 spines are visible on the appendage.

427

428 Remarks: This specimen is no longer considered Anomalocaris pennsy/vanica as the

429 podomeres are square to elongate rectangular in shape (as opposed to tall rectangles), and

430 the ventral endites, although they lack auxiliary spines, do not alternate long/short on

431 even/odd numbered podomeres and instead reduce in length along the appendage.

432

433 This specimen is instead considered to belong to the genus Tamisiocaris as it has long,

434 paired, ventral endites which do not alternate long/short, similar to T. borealis from Sirius

435 Passet. The approximate square-shape of the podomeres is consistent with the distal end of

436 known Tamisiocaris specimens from Sirius Passet. Just as in Tamisiocaris borealis, this

437 specimen lacks any dorsal spines, which would instead indicate affinities with Anomalocaris

438 briggsi. There is no evidence that this specimen bears auxiliary spines, which are visible in

439 some specimens of $T$. borealis (although not the type specimen), and it is only known as a

440 partial appendage so the number of podomeres cannot be ascertained. Because of this the

441 specimen is left in open nomenclature as $T$. aff. borealis.

442

443 This is the youngest Tamisiocaris known (Cambrian Stage 4) and the first from outside the

444 Sirius Passet Lagerstätte (Cambrian Stage 3, Greenland). Tamisiocaris is still only known 445 from Laurentia. 
Family AMPLECTOBELUIDAE Vinther et al. 2014

Genus AMPLECTOBELUA Hou et al. 1995

449

450

\author{
Amplectobelua aff. symbrachiata
}

451

Figure 5

452

453

1938 Anomalocaris pennsylvanica; Resser and Howell, pl. 13, fig. 6

454 1953 Anomalocaris pennsylvanica; Roger, pl. 2 fig. 4

455 1979 Anomalocaris pennsylvanica; Briggs, pl. 79 figs 4, 6, text-figs 17, 19

456

457 Material. Isolated frontal appendages, Kinzers Formation, Pennsylvania, USA, YPM 14388

458 (part) and PA 387 (counterpart) locality 12x; PA390 (part and counterpart) locality 22L. 459

460 Description: Two Amplectobelua appendages can be recognized from the Kinzers Formation.

461 YPM 14388 (Fig. 5a, b), with counterpart PA387, is a complete isolated appendage with 12

462 podomeres. The podomeres are tall and rectangular but become more square towards the

463 distal end (compare pd5 to pd10 in Fig. 5b). A long and stout endite with the base of three

464 spines preserved is present on the most proximal podomere (Fig 5b, pd1, en1). The central

465 spine base is the thickest, with the proximal-most spine preserved in its entirety. Short and

466 paired spinose endites are present on the remaining podomeres, although most are

467 incomplete, and the endite on pd6 shows that they were simple spines shorter than the

468 podomere to which they attached (Fig. 5b, en6). The broken base on pd5 is wider than the

469 broken base of $\mathrm{pd} 3$, implying that the ventral endite on this pd5 was more robust than that 
470 of pd3 (en3, en5, Fig. 5b). The distalmost two podomeres (pd11-12) bear robust paired

471 dorsal spines which are recurved following the outline of the appendage and combine with

472 a reduced terminal spine to make a claw-like termination (Fig. 5b, ds \& ts). PA 390 (Fig. 5c,

473 d) is a partial appendage with the 10 most distal podomeres visible. Podomeres are tall and

474 rectangular, but become more square at the distal end (compare Fig. $5 d$, pd4 to pd9 and

475 pd12). All the ventral endites are short (e.g. Fig. 5b, en6-8) and robust recurved dorsal

476 spines are visible at the distal end (Fig. 5d, ds) alongside a reduced terminal spine (Fig. 5d,

477 ts). In both YPM 14388 and PA 390 some smaller and straight dorsal spines are visible

478 proximal to the robust dorsal spines (e.g. Fig. 5b, ds10).

479

480 Remarks: These specimens are no longer considered Anomalocaris pennsylvanica as the

481 dorsal spines at the distal end are paired and much more robust, the ventral endites along

482 the appendage are short, and the number of podomeres (where they can be counted) is 12

483 instead of 14. This interpretation differs slightly from the previous descriptions, where both

484 these appendages were interpreted to have 14 podomeres (Briggs 1979, plate 79 figs 4, 6;

485 text-figs 17, 19). The podomere labelled as j6 of PA 390 (Briggs 1979, plate 79 fig 4, text fig

486 17) is here interpreted as the eighth podomere, j1 and j2 of YPM 14388 (Briggs 1979, plate

48779 fig 6, text fig 19) are interpreted as being an enlarged $1^{\text {st }}$ podomere (Fig. 5b, pd1) as no

488 podomere boundary is visible here (none was drawn in Briggs 1979, text fig 19). The

489 structure labelled as j14 is here interpreted as one of a pair of robust dorsal spines (Fig. 5b, $490 \mathrm{ds12).}$

491

492 A number of lines of evidence support the reinterpretation of these two appendages as

493 Amplectobelua, including the presence of paired but short ventral endites along the 
494 majority of the appendage, the rectangular podomeres, and paired robust dorsal spines at

495 the distal end. In addition YPM 14388 has an enlarged ventral endite on pd1 (pd1 is not

496 preserved in PA 390), and the base of the endite on pd5 appears more robust than that of

497 pd3. These specimens are most similar to Amplectobelua symbrachiata, as they both bear

498 short ventral endites along the appendage alternating long/short and the morphology of the

499 enlarged ventral endite is constructed of three spines with the thickest in the centre, unlike

500 in Amplectobelua stephenensis where there is only one very enlarged and thickened spine

501 on the most proximal podomere. Amplectobelua symbrachiata also bears smaller dorsal

502 spines proximally to the enlarged recurved dorsal spines, as is also seen in both the

503 specimens from the Kinzers Formation. The material from the Kinzers however does not

504 have exactly the same morphology as Amplectobelua symbrachiata, because it has a

505 reduced terminal spine, not present in the Chengjiang species, and evidence for paired

506 dorsal spines not reported from the Chinese animal, but a feature known from

507 Amplectobelua stephenensis. The podomeres become more square shaped towards the

508 distal end in the Kinzers species, a feature not seen in either Amplectobelua symbrachiata or

509 Amplectobelua stephenensis.

510

511 The preservation does not allow all the anatomical features to be recognized. For example

512 the morphology of the enlarged ventral endite is not completely known, specifically the

513 length of the central thickened spine. In addition there is no evidence of the shaft, which is

514 expected to be of three podomeres in Amplectobleua. For these reasons this species is left

515 in open nomenclature.

516 
517 These are the first Amplectobelua from the Cambrian Stage 4, the first from the USA, and

518 the oldest in Laurentia. Amplectobelua was previously known from the Stage 3 of China and

519 Stage 5 of Canada. They bear more similarity to the Chinese species, Amplectobelua

520 symbrachiata than the Canadian Amplectobelua stephenensis perhaps indicating an invasion

521 by the Chinese species at the end of Stage 3 followed by a subsequent radiation in

522 Laurentia.

523

524 5. Discussion

525

526 5.a. Diverse feeding strategies of Kinzers Formation Radiodonta

527

528 The Kinzers Formation contains one species of Anomalocaris, Amplectobelua, Tamisiocaris,

529 and tentatively Laminacaris (Fig. 6; Table 2). The presence of a number of different

530 radiodonts from the same site is not unusual for Cambrian Lagerstätten, and supports

531 previous suggestions that these stem-group euarthropods employed a number of different

532 feeding strategies (Daley \& Budd 2010; Vinther et al. 2014; Van Roy et al. 2015).

533 Anomalocaris pennsy/vanica would have used its flexible appendages to actively grab likely

534 soft-bodied prey and slice it with the simple elongate ventral endites. Amplectobelua aff.

535 symbrachiata would have used its more robust proximal ventral endite and thickened distal

536 dorsal spines to more tightly hold and slice or potentially crush prey. The presence of

537 reduced ventral endites between the proximal and distal end would have allowed the

538 appendage to coil more tightly, allowing the distal and proximal robust spines to come

539 together more easily in a slicing or crushing motion. Tamisiocaris aff. borealis may not have

540 been a filter feeder targeting plankton like the Sirius Passet species if the lack of fine 
541 auxiliary spines is not an artefact of preservation, and so instead may have sifted or raked

542 through the sediment. It is also possible that it filtered larger particles than the Greenland

543 species, and so did not require auxiliary spines. ?Laminacaris sp. likely used its straight

544 ventral endites with auxiliary spines to function as a net-like apparatus, potentially similar to

545 some hurdiids, and as suggested for Anomalocaris briggsi from the Emu Bay Shale (Daley et

546 al. 2013b). Its longer ventral spines, and lack of clear alternating long/short ventral endites

547 make a raptorial feeding strategy similar to that inferred for Laminacaris chimera, less likely.

549 5. b. Importance of the Kinzers Formation

550

551 Radiodonta are known from other Cambrian Series 2, Stage 4, Konservat-Lagerstätten,

552 however the Kinzers Formation ( $30^{\circ} \mathrm{S}$ palaoelatitude, Laurentia) is uniquely important for

553 understanding the palaeogeographic and palaeolatitudinal distribution of these animals (Fig.

554 7) because of the high diversity of taxa found there. Radiodonta are known from four other

555 broadly coeval formations in North America from Laurentia (all equatorial): Latham Shale

556 (Briggs and Mount 1982), Comet Shale Member, Pioche Formation (Lieberman 2003), Eagar

557 Formation, Cranbrook Shale (Briggs 1979), and Pyramid Shale Member, Carrara Formation

558 (unpublished material). Radiodonta have also been reported from two formations of this

559 age on the South China paleocontinent (ca. $30^{\circ} \mathrm{N}$ palaeolatitude): the Balang Formation (Liu

560 2013), and Wulongqing Formation (Wang et al. 2013); and from two Gondwanan sites: the

561 Emu Bay Shale in Australia (ca. 15 N palaeolatitude) (Nedin 1995; Daley et al. 2013b) and

562 Valdemiedes Formation in Spain (ca. 60 S palaeolatitude) (Pates \& Daley 2017) (Table 3; Fig. 563 7). 
565 The recognition of four different radiodont taxa, from at least three different families,

566 means that the Kinzers Formation has the most diverse Radiodonta fauna of all the Stage 4

567 Konservat-Lagerstätten, despite relatively few specimens being known - especially

568 compared to the Emu Bay Shale and Wulongqing Formation (Table 3). The fauna contains

569 links with both the older Sirius Passet (Tamisiocaris) and Chengjiang (Amplectobelua,

570 Anomalocaris and Laminacaris) faunas, as well as the younger Burgess Shale (Amplectobelua

571 and Anomalocaris). It has a named endemic species with Anomalocaris pennsylvanica, with

572 at least two (and potentially all four) of its radiodont species not yet known from other

573 localities. Its unique position at a non-equatorial latitude in Laurentia, as well as the lack of

574 any Tier 1 Burgess Shale Type deposits (sensu Gaines 2014) in the Cambrian Series 2 Stage 4

575 highlights the importance of the Kinzers Formation. The previous categorization of the

576 Kinzers Formation as a Tier 3 Lagerstätten was because of limited rock exposure, not

577 fossilization conditions (Gaines 2014). The recovery of a highly diverse radiodont fauna from

578 a relatively low number of specimens suggests that further exploration of the Kinzers

579 Formation could yield new taxa rapidly. Caryosyntrips and Hurdia could also be present in

580 the Kinzers Formation, as the former is present at the higher latitude coeval Valdemiedes

581 Formation (Spain) and equatorial Laurentia in Stage 5 (Pates \& Daley 2017), and the latter

582 present at the coeval equatorial Laurentian Pioche Formation (unpublished material) and

583 higher latitude Stage 5 Bohemia (Chlupáč \& Kordule 2002; Daley et al. 2013a). Their absence

584 might also be due to similar inferred feeding niches are already occupied in the Kinzers

585 Formation by Amplectobelua, Tamsiocaris, and ?Laminacaris, a result of unfavourable

586 environmental conditions, or reflect the dominance of Amplectobeluidae, Anomalocarididae

587 and Tamisiocarididae in older, Series 2, deposits and later dominance of Hurdiidae in Series

5883. 
589

590

\section{Conclusions}

591

592 The vast progress in our understanding of the diversity of Radiodonta since the previous

593 study of Kinzers Formation radiodonts allowed the identification of Tamisiocaris and

594 Amplectobelua in the USA for the first time. These reinterpretations mean that the Kinzers

595 Formation can now be considered a Tier 2 BST with more than 10 soft-bodied taxa (sensu

596 Gaines 2014), and has the highest known diversity of Radiodonta of any Cambrian Series 2

597 Stage 4 Konservat-Lagerstätten. The radiodonts found in the Kinzers Formation are

598 potentially all endemic species, and include the youngest Tamisiocaris known, and the

599 oldest Amplectobelua in Laurentia. This highlights the importance of the Kinzers Formation

600 in understanding the diversity and evolution of Cambrian Radiodonta, and supports further

601 exploration of this Lagerstätten.

602

\section{Acknowledgements}

604 We would like to thank the editor, Paul Upchurch, and two anonymous referees for their

605 comments on the manuscript. SP is funded by an Oxford-St Catherine's Brade-Natural

606 Motion Scholarship. A Palaeontological Association Sylvester-Bradley Award (PA-SB201503)

607 allowed travel to Franklin Marshall College, USNM and YPM. For facilitating access to

608 specimens, we thank Susan Butts and Jessica Utrup at YPM, Mark Florence at USNM, and

609 Roger DK Thomas at Franklin Marshall. This manuscript benefitted from discussions with P.

610 Cong, G. Edgecombe, R. R. Gaines, B. S. Lieberman, and R. D. K. Thomas.

611

612 Declaration of Interest 
7

8

9

613 None.

614

615 References

616

617 Allison, P. A. \& Briggs, D. E. G. 1993. Exceptional fossil record: Distribution of soft-tissue

618 preservation through the Phanerozoic. Geology 21, 527-530.

619

620 Briggs, D. E. G. 1978. A new trilobite-like arthropod from the Lower Cambrian Kinzers

621 Formation, Pennsylvania. Journal of Paleontology 52, 132-140.

622

623 Briggs, D. E. G. 1979. Anomalocaris, the largest known Cambrian arthropod. Palaeontology

$62422,631-664$.

625

626 Briggs, D. E. G. \& Mount, J. D. 1982. The occurrence of the giant arthropod Anomalocaris in 627 the Lower Cambrian of southern California, and the overall distribution of the genus. Journal 628 of Paleontology 56, 1112-1118.

629

630 Briggs, D. E. G., Lieberman, B.S., Hendricks, J.R., Halgedahl, S.L. \& Jarrard, R.D., 2008, Middle

631 Cambrian arthropods from Utah. Journal of Paleontology 82, 238-254.

632

633 Campbell, L. \& Kauffman, M. E. 1969. Olenellus fauna of the Kinzers Formation, 634 southeastern Pennsylvania. Proceedings of the Pennsylvania Academy of Science 43, 172635176.

636 
637 Chen, J., Ramsköld, L. \& Zhou, G. 1994. Evidence for monophyly and arthropod affinity of 638 Cambrian giant predators. Science 264, 1304-1308.

639

640 Chlupáč, I. \& Kordule, V. 2002. Arthropods of Burgess Shale type from the Middle Cambrian 641 of Bohemia (Czech Republic). Bulletin of the Czech Geological Survey 77, 167-182.

642

643 Collins, D. 1996. The "evolution" of Anomalocaris and its classification in the arthropod class

644 Dinocarida (nov.) and order Radiodonta (nov.). Journal of Paleontology 70, 280-293.

645

646 Cong, P., Ma, X., Hou, X., Edgecombe, G. D. \& Strausfield, N. J. 2014. Brain structure resolves

647 the segmental affinity of anomalocaridid appendages. Nature 513, 538-542.

648

649 Cong, P., Daley, A.C., Edgecombe, G.D., Hou, X. \& Chen, A. 2016. Morphology of the 650 radiodontan Lyrarapax from the early Cambrian Chengjiang biota. Journal of Paleontology $65190,663-671$.

652

653 Cong, P., Daley, A.C., Edgecombe, G. D. \& Hou, X. 2017. The functional head of the Cambrian 654 radiodontan (stem-group Euarthropoda) Amplectobelua symbrachiata. BMC Evolutionary 655 Biology 17, 208.

656

657 Cong, P., Edgecombe, G. D., Daley, A. C., Guo, J., Pates, S. \& Hou, X. G. 2018. New

658 radiodontans with gnathobase-like structures from the Cambrian Chengjiang Biota and

659 implications for the systematics of Radiodonta. Papers in Palaeontology, in press. doi:

$660 \quad 10.1002 / s p p 2.1219$. 
661

662 Conway Morris, S. 1977. Fossil priapulid worms. Special Papers in Palaeontology 20, 1-155.

663

664 Daley, A. C., Budd, G.E., Caron, J.B., Edgecombe, G. D. \& Collins, D. 2009. The Burgess Shale

665 anomalocaridid Hurdia and its significance for early euarthropod evolution. Science 323,

$666 \quad 1597-1600$.

667

668 Daley, A. C., \& Budd, G. E. 2010. New anomalocaridid appendages from the Burgess Shale, 669 Canada. Palaeontology 53, 721-738.

670

671 Daley, A. C., \& Peel, J. S. 2010. A possible anomalocaridid from the Cambrian Sirius Passet

672 lagerstätte, North Greenland. Journal of Paleontology 84, 352-355.

673

674 Daley, A. C., Budd, G. E., \& Caron, J. B. 2013a. Morphology and systematics of the

675 anomalocaridid arthropod Hurdia from the Middle Cambrian of British Columbia and Utah.

676 Journal of Systematic Palaeontology 11, 743-787.

677

678 Daley, A. C., Paterson, J. R., Edgecombe, G. D., García-Bellido, D. C. \& Jago, J. B. 2013b. New

679 anatomical information on Anomalocaris from the Cambrian Emu Bay Shale of South

680 Australia and a reassessment of its inferred predatory habits. Palaeontology 56, 971-990.

681

682 Daley, A. C., \& Legg, D. A. 2015. A morphological and taxonomic appraisal of the oldest

683 anomalocaridid from the Lower Cambrian of Poland. Geological Magazine 152, 949-955.

684 
685 Dunbar, C. O. 1925. Antennae in Olenellus getzi n. sp.. American Journal of Science 52, 303686308.

687

688 Gaines, R.R. 2014. Burgess Shale-type preservation and its distribution in space and time.

689 Reading and Writing of the Fossil Record: Preservational Pathways to Exceptional

690 Fossilization. Paleontological Society Papers 20, 123-146.

691

692 García-Bellido, D. \& Conway Morris, S. 1999. New Fossil Worms from the Lower Cambrian of 693 the Kinzers Formation, Pennsylvania, with Some Comments on Burgess Shale-Type

694 Preservation. Journal of Paleontology 73, 394-402.

695

696 Guo, J., Pates, S., Cong, P., Daley, A. C., Edgecombe, G. D., Chen, T., \& Hou, X. G . A new

697 radiodont (stem Euarthropoda) frontal appendage with a mosaic of characters from the

698 Cambrian (Series 2 Stage 3) Chengjiang biota. Papers in Palaeontology. In press.

699

700 Hou, X. G., Bergström, J. \& Ahlberg, P. 1995. Anomalocaris and other large animals in the

701 Lower Cambrian Chengjiang fauna of southwest China. GFF 117, 163-183.

702

703 Kühl, G., Briggs, D. E. G. \& Rust, J. 2009. A great appendage arthropod with a radial mouth

704 from the Lower Devonian Hunsrück Slate, Germany. Science 323, 771-773.

705

706 Lankester E. R. 1904. The structure and classification of Arthropoda. Quarterly Journal of

707 Microscopical Science 47, 523-582.

708 
709 Lerosey-Aubril, R., Hegna, T. A., Babcock, L. E., Bonino, E. \& Kier, C. 2014. Arthropod

710 appendages from the Weeks Formation Konservat-Lagerstätte: new occurrences of

711 anomalocaridids in the Cambrian of Utah, USA. Bulletin of Geosciences 89, 269-282.

712

713 Lieberman, B. S. 2003. A new soft-bodied fauna: the Pioche Formation of Nevada. Journal of

714 Paleontology 77, 674-690.

715

716 Liu, J., Lerosey-Aubril, R., Steiner, M., Dunlop, J. A., Shu, D. \& Paterson, J. R. 2018. Origin of

717 raptorial feeding in juvenile Euarthropods revealed by a Cambrian radiodontan. National

718 Science Review nwy057. doi: 10.1093/nsr/new057.

719

720 Liu, Q. 2013. The first discovery of anomalocaridid appendages from the Balang Formation

721 (Cambrian Series 2) in Hunan, China. Alcheringa 37, 1-6.

722

723 Nedin, C. 1995. The Emu Bay Shale, a Lower Cambrian fossil Lagerstätten, Kangaroo Island.

724 Memoirs of the Association of Australasian Palaeontologists 18, 133-141.

725

726

Pates, S., Daley, A. C. \& Ortega-Hernández, J. 2018. Response to comment “Aysheaia prolata

727 from the Wheeler Formation (Drumian, Cambrian) is a frontal appendage of the

728 radiodontan Stanleycaris" with the formal description of Stanleycaris. Acta Palaeontologica

729 Polonica 63, 105-110.

730

731 Pates, S., Daley, A. C. \& Lieberman, B.S. 2018b. Hurdiid radiodontans from the middle

732 Cambrian (Series 3) of Utah. Journal of Paleontology 92, 99-113. 
733

734 Pates, S., Daley, A. C. \& Ortega-Hernández, J. 2017. Aysheaia prolata from the Wheeler

735 Formation (Drumian, Cambrian) is a frontal appendage of the radiodontan Stanleycaris. Acta

736 Palaeontologica Polonica 62, 619-625.

737

738 Pates, S. \& Daley, A.C. 2017. Caryosyntrips: a radiodontan from the Cambrian of Spain, USA

739 and Canada. Papers in Palaeontology 3, 461-470.

740

741 Raymond, P.E. 1935. Leanchoilia and other mid-Cambrian Arthropoda. Bulletin of the

742 Museum of Comparative Zoology at Harvard College 76, 205-230.

743

744 Resser, C. E. 1929. New lower and middle Cambrian Crustacea. Proceedings of the United

745 States National Museum 76, 1-18.

746

747 Resser, C. E. \& Howell, B. F. 1938. Lower Cambrian Olenellus Zone of the Appalachians.

748 Bulletin of the Geological Society of America 49, 195-248.

749

750 Rigby, J. K. 1987. Early Cambrian sponges from Vermont and Pennsylvania, the only ones

751 described from North America. Journal of Paleontology 61, 451-461.

752

753 Roger, J. 1953. Sous-classe des Malacostracés. In Traité de Paléontologie (ed. Piveteau, J.)

754 pp. 309-378. Paris.

755 
756 Schneider, C. A., Rasband, W. S. \& Eliceiri, K. W. 2012. NIH Image to Image J: 25 years of

757 image analysis. Nature Methods 9, 671-675.

758

759 Scotese, C. R. 2016. PALEOMAP PaleoAtlas for GPlates and the PaleoData Plotter Program,

760 PALEOMAP Project, http://www.earthbyte.org/paleomap- paleoatlas-for-gplates/

761

762 Skinner, E. S. 2005. Taphonomy and depositional circumstances of exceptionally preserved

763 fossils from the Kinzers Formation (Cambrian), southeastern Pennsylvania.

764 Palaeogeography, Palaeoclimatology, Palaeoecology 220, 167-192.

765

766 Van Roy, P., Daley, A. C. \& Briggs, D. E. G. 2015. Anomalocaridid trunk limb homology

767 revealed by a giant filter-feeder with paired flaps. Nature $\mathbf{5 2 2}, \mathbf{7 7 - 8 0}$.

768

769 Vannier, J., Caron, J. B., Yuan, J. L., Briggs, D. E. G., Collins, D., Zhao, Y. L. \& Zhu, M. Y. 2007.

770 Tuzoia: morphology and lifestyle of a large bivalved arthropod of the Cambrian seas. Journal

771 of Paleontology, 81, 445-471.

772

773 Vinther, J., Stein, M., Longrich, N. R. \& Harper, D. A. 2014. A suspension-feeding

774 anomalocarid from the Early Cambrian. Nature 507, 496-499.

775

776 Wang, Y., Huang, D. \& Hu, S. 2013. New anomalocardid frontal appendages from the

777 Guanshan biota, eastern Yunnan. Chinese Science Bulletin 58, 3937-3942.

778 
779 Whiteaves, J.F. 1892. Description of a new genus and species of phyllocarid crustacean from

780 the Middle Cambrian of Mount Stephen, British Columbia. Canadian Record of Science 5,

$781 \quad 205-208$.

782

783 Whittington, H. B. \& Briggs, D. E. G. 1985. The largest Cambrian animal, Anomalocaris, 784 Burgess Shale, British Columbia. Philosophical Transactions of the Royal Society of London.

785 Series B, Biological Sciences 309, 569-609.

786

787 Figure Captions

788

789

Figure 1. Schematic radiodont frontal appendage showing terminology used. Podomeres in

790

dark grey, ventral endites in light grey. (a) sagittal view. Abbreviations: $\vartheta$, angle between

791

shaft and distal articulated region on dorsal surface; 1 , post-shaft podomere; 3 and 5 , third

792

and fifth podomere in the distal articulated region. For anomalocaridids, the ventral endites

793

on 3 are longer than those on 5 , for amplectobeluids the ventral endites on 5 are longer

794

than those on 3. In hurdiids all podomeres from 1 to 5 will have enlarged endites of the

795

same morphology and equal length. (b) frontal view of non-hurdiid podomere, showing

796

relative width and separate attachment of two ventral endites to one podomere. (c) frontal

797 view of hurdiid podomere showing relative width and attachment of one ventral endite to

798 one podomere.

799

800 Figure 2. ?Laminacaris sp. from the Kinzers Formation. (a,b) USNM 213693; (c,d) USNM

801 90827A. Scale bars $10 \mathrm{~mm}$. Abbreviations: enX, ventral endite X; pdX, podomere X.

802 
803 Figure 3. Anomalocaris pennsylvanica from the Kinzers Formation. (a,b) Holotype USNM

804 80487; (c,d) YPM 10425; (e,f) USNM 255611. Scale bars 10 mm. Abbreviations: dsX, dorsal

805 spine $\mathrm{X}$; enX, ventral endite $\mathrm{X}$; pdX, podomere $\mathrm{X}$; ?S, putative shaft podomere; ts, terminal 806 spine.

807

808 Figure 4. Tamisiocaris aff. borealis from the Kinzers Formation. (a,b) PA 388. Scale bars 10

$809 \mathrm{~mm}$. Abbreviations: en, ventral endite; ?pdX, podomere $\mathrm{X}$, inferred from complete $T$.

810 borealis appendages.

811

812 Figure 5. Amplectobelua aff. symbrachiata from the Kinzers Formation. (a,b) YPM 14388;

813 (c,d) PA 390. Scale bars $10 \mathrm{~mm}$. Abbreviations: ds, dorsal spines; enX, ventral endite X ; pdX, 814 podomere $X$.

815

816 Figure 6. Reconstructions of Radiodonta from the Kinzers Formation, and other frontal

817 appendages with similar morphology. (a) Anomalocaris pennsylvanica; (b) Anomalocaris

818 canadensis; (c) Tamisiocaris aff. borealis; (d) Tamisiocaris borealis; (e) Anomalocaris briggsi;

819 (f) Amplectobelua aff. symbrachiata; (g) Amplectobelua symbrachiata; (h) Amplectobelua

820 stephenensis; (i) ?Laminacaris sp; (j) Laminacaris chimera. Dotted lines show parts of

821 appendage that are not preserved. Line drawings (b), (g), and (h) adapted from Daley \&

822 Budd (2010, text-fig. 1A, F, G), (d) adapted from Vinther et al. (2014, extended data fig. 6a),

823 (e) adapted from Daley et al. (2013b, fig. 2), and (j) redrawn from Guo et al. (in press, fig.

$8243 A)$. 
826 Figure 7. Palaeogeographic reconstruction to 510 Ma from GPlates (Scotese 2016). White

827 star shows Kinzers Formation; black stars show other Stage 4 sites where radiodont fossils

828 have been found. Abbreviations: B, Balang Formation; Ca, Carrara Formation; $\mathrm{Cr}$, Cranbrook

829 Formation; E, Emu Bay Shale; K, Kinzers Formation; L, Latham Shale; P, Pioche Formation; V,

830 Valdemiedes Formation; W, Wulongqing Formation.

831

832

833 


1
2
3
4
5
5
6
7
8
9
10
11
12
13
14
15
16
17
18
19
20
21
22
23
24
25
26
27
28
29
30
31
32
33
34
35
36
37
38
39
40
41
42
43
44
45
46
47


Table 1: Frontal appendage characters used to distinguish radiodont families

\begin{tabular}{|c|c|c|c|c|c|c|c|c|c|c|}
\hline & \multicolumn{6}{|c|}{ Podomeres and numbers of ventral endites } & \multicolumn{4}{|c|}{ Morphology of large ventral endite(s) } \\
\hline & $\begin{array}{l}\text { \# pd. } \\
\text { in } \\
\text { shaft }\end{array}$ & $\begin{array}{l}\text { \# pd. in distal } \\
\text { articulated } \\
\text { region }\end{array}$ & $\begin{array}{c}\text { Triangular } \\
\text { membrane } \\
\text { between pd. }\end{array}$ & $\begin{array}{c}\text { \# } \\
\text { rows } \\
\text { en. }\end{array}$ & $\begin{array}{c}\text { \# of } \\
\text { longest } \\
\text { en. }\end{array}$ & $\begin{array}{l}\text { en. in d.a.r. } \\
\text { alternate } \\
\text { long/short }\end{array}$ & as. paired & $\begin{array}{l}\text { as. increase in } \\
\text { size from base } \\
\text { to tip }\end{array}$ & $\begin{array}{l}\text { \# Large } \\
\text { as. }\end{array}$ & $\begin{array}{l}\text { Small as. } \\
\text { between } \\
\text { large as. }\end{array}$ \\
\hline Amplectobeluidae & 3 & $12 / 13$ & Yes & 2 & 1 & Yes & Yes & No & $0 / 2$ & No \\
\hline Anomalocarididae & $1-3$ & 13 & Yes & 2 & 1 & Yes & Yes & No & $0 / 2$ & No \\
\hline Hurdiidae & $1 / 2$ & $8-10$ & No & 1 & 5 & No & No & Yes & $0-5$ & Hurdia only \\
\hline Laminacaris & 2 & 13 & Yes & $1 ?$ & 1 & Yes & No & Yes & 5 & Yes \\
\hline Tamisiocarididae & ?1 & $13 / 17$ & Yes & 2 & $0 / 1^{*}$ & No & Yes* & ?Yes* & ?* & No* \\
\hline \multicolumn{11}{|c|}{$\begin{array}{l}\text { *A. briggsi bears an enlarged post-shaft endite, and Tamisiocaris does not. Hence all characters referring to the morphology of the large ventral endite for } \\
\text { this family refer to A. briggsi only. Abbreviations: as, auxiliary spine; d.a.r., distal articulated region; en, ventral endite; pd, podomere }\end{array}$} \\
\hline 5 & & & & & & & & & & \\
\hline
\end{tabular}


Table 2: Current and previous interpretations of Kinzers radiodont appendages.

\begin{tabular}{|c|c|c|c|c|c|}
\hline Catalogue \# & Fig. & Site & Previous interpretation & Current interpretation & References \\
\hline $\begin{array}{l}\text { USNM 213693, } \\
\text { PA } 394 \text { (cpt) }\end{array}$ & $1 a, b$ & $22 \mathrm{~L}$ & Anomalocaris? cf. pennsylvanica & ?Laminacaris sp. & Briggs 1979 pl. 81 figs. 9,10, text-fig. 33. \\
\hline $\begin{array}{l}\text { USNM 90827A, } \\
\text { PA } 393 \text { (cpt) }\end{array}$ & $1 c, d$ & $22 \mathrm{~L}$ & Anomalocaris? cf. pennsylvanica & ?Laminacaris sp. & Briggs 1979 pl. 81 fig. 11, text-fig. 34. \\
\hline $\begin{array}{l}\text { USNM } 80487 \\
\text { (part and cpt) }\end{array}$ & $2 a, b$ & $12 x$ & $\begin{array}{c}\text { Anomalocaris pennsylvanica } \\
\text { (holotype) }\end{array}$ & Anomalocaris pennsy/vanica (holotype) & $\begin{array}{l}\text { Resser 1929, pl. 5, fig. 5; pl. 79, fig. 5; Resser } \\
\text { and Howell 1938, pl. 10, fig. 4; Briggs } 1979 \text { pl. } \\
79 \text { fig. 5, text-fig. } 18 .\end{array}$ \\
\hline YPM 10425 & $2 c, d$ & $12 x$ & Anomalocaris pennsy/vanica & Anomalocaris pennsylvanica & Briggs 1979 \\
\hline USNM 255611 & $2 e, f$ & $22 \mathrm{~L}$ & Anomalocaris pennsylvanica & Anomalocaris pennsy/vanica & Briggs 1979 \\
\hline $\begin{array}{l}\text { USNM 90827, } \\
\text { PA } 388 \text { (cpt) }\end{array}$ & 3 & $22 \mathrm{~L}$ & Anomalocaris pennsylvanica & Tamisiocaris aff. borealis & $\begin{array}{l}\text { Resser and Howell 1938, pl. 13, fig. 5; Briggs } \\
\text { 1979* }\end{array}$ \\
\hline $\begin{array}{l}\text { YPM 14388, } \\
\text { PA } 387 \text { (cpt) }\end{array}$ & $4 a, b$ & $12 x$ & Anomalocaris pennsylvanica & Amplectobelua aff. symbrachiata & $\begin{array}{l}\text { Resser and Howell 1938, pl. 13, fig. 6; Roger } \\
\text { 1953, pl. } 2 \text { fig. 4; Briggs } 1979 \text { pl. } 79 \text { fig. 6, text- }\end{array}$ \\
\hline PA 390 (part and cpt) & $4 c, d$ & $22 \mathrm{~L}$ & Anomalocaris pennsylvanica & Amplectobelua aff. symbrachiata & Briggs 1979, pl. 79 fig. 4, text fig 17 \\
\hline PA 389 & - & $22 \mathrm{~L}$ & Anomalocaris pennsylvanica & Euarthropoda indet. & Briggs 1979 \\
\hline PA 395a & - & $22 \mathrm{~L}$ & ?Anomalocaris pennsylvanica & Indet. & Briggs 1979 \\
\hline YPM 63295 & - & $12 x$ & Anomalocaris pennsylvanica & Euarthropoda indet. & Lieberman 2003 \\
\hline
\end{tabular}


Table 3: Cambrian Series 2, Stage 4 Radiodonta bearing Konservat-Lagerstätten.

\begin{tabular}{|c|c|c|c|c|c|}
\hline Formation & Palaeocontinent & Palaeolatitude & \# Specimens & \# Radiodont taxa & References \\
\hline Kinzers Formation & Laurentia & $30^{\circ} \mathrm{S}$ & 8 & 4 & Resser 1929; Briggs 1979; this study \\
\hline Carrara Formation & Laurentia & $0^{\circ}$ (equator) & (4) & (1) & Unpublished material \\
\hline Cranbrook Shale & Laurentia & $0^{\circ}$ (equator) & 2 & 1 & Briggs 1979 \\
\hline Latham Shale & Laurentia & $0^{\circ}$ (equator) & $3(+1)$ & 1 & Briggs and Mount 1982 \\
\hline Pioche Formation & Laurentia & $0^{\circ}$ (equator) & $24(+1)$ & $1(+1)$ & Lieberman 2003; unpublished material \\
\hline Emu Bay Shale & Gondwana & $15^{\circ} \mathrm{N}$ & 69 & 2 & Nedin 1995; Daley et al. 2013b \\
\hline Valdemiedes Formation & Gondwana & $60^{\circ} \mathrm{S}$ & 1 & 1 & Pates \& Daley 2017 \\
\hline Balang Formation & South China & $30^{\circ} \mathrm{N}$ & 2 & 2 & Liu 2013 \\
\hline Wulongqing Formation & South China & $30^{\circ} \mathrm{N}$ & 48 & 2 & Wang et al. 2013 \\
\hline
\end{tabular}


a

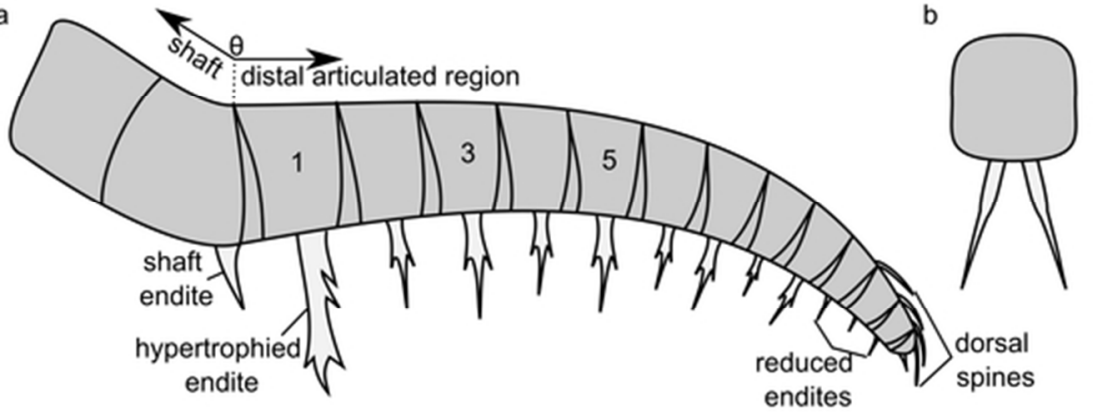

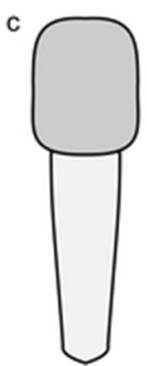

Figure 1. Schematic radiodont frontal appendage showing terminology used. Podomeres in dark grey, ventral endites in light grey. (a) sagittal view. Abbreviations: $\vartheta$, angle between shaft and distal articulated region on dorsal surface; 1 , post-shaft podomere; 3 and 5, third and fifth podomere in the distal articulated region. For anomalocaridids, the ventral endites on 3 are longer than those on 5, for amplectobeluids the ventral endites on 5 are longer than those on 3. In hurdiids all podomeres from 1 to 5 will have enlarged endites of the same morphology and equal length. (b) frontal view of non-hurdiid podomere, showing relative width and separate attachment of two ventral endites to one podomere. (c) frontal view of hurdiid podomere showing relative width and attachment of one ventral endite to one podomere. 

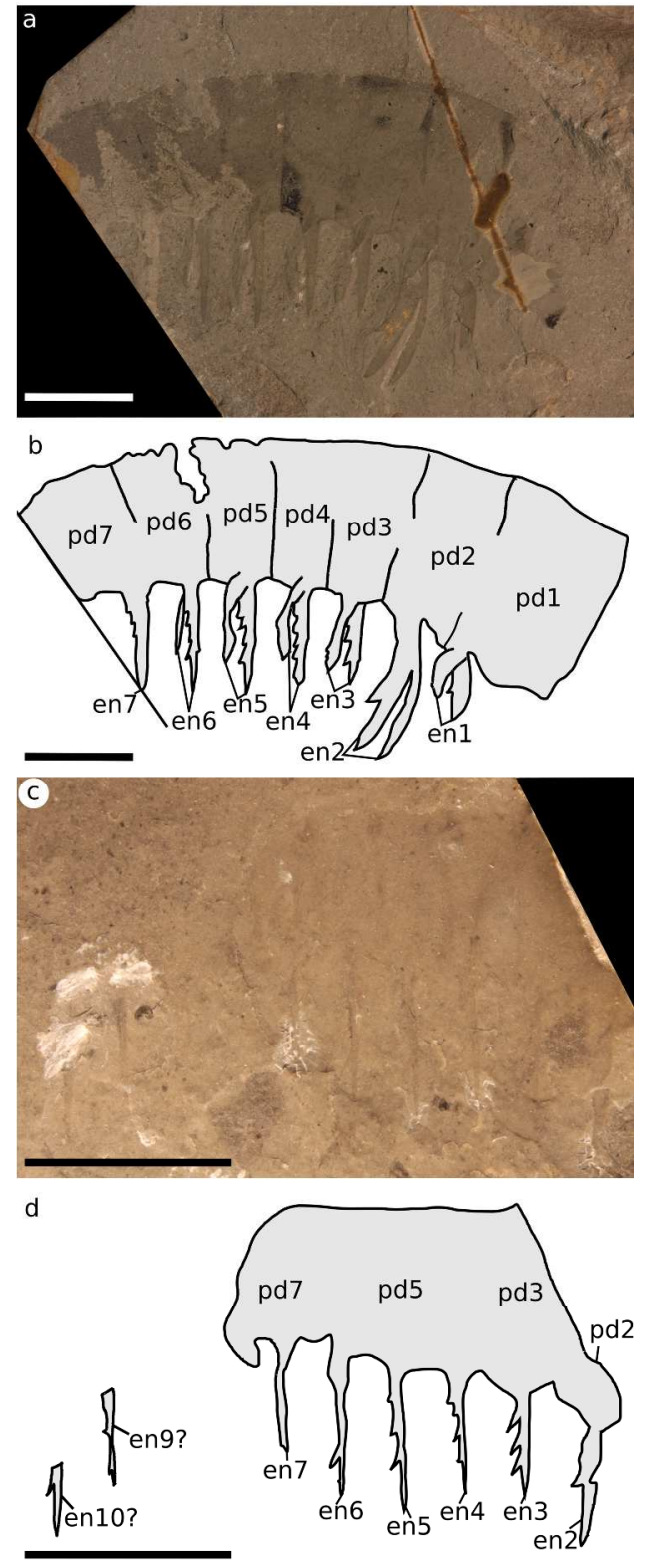

Figure 2. ?Laminacaris sp. from the Kinzers Formation. (a,b) USNM 213693; (c,d) USNM 90827A. Scale bars $10 \mathrm{~mm}$. Abbreviations: enX, ventral endite X; pdX, podomere X.! + !! +

$202 \times 510 \mathrm{~mm}(300 \times 300$ DPI) 

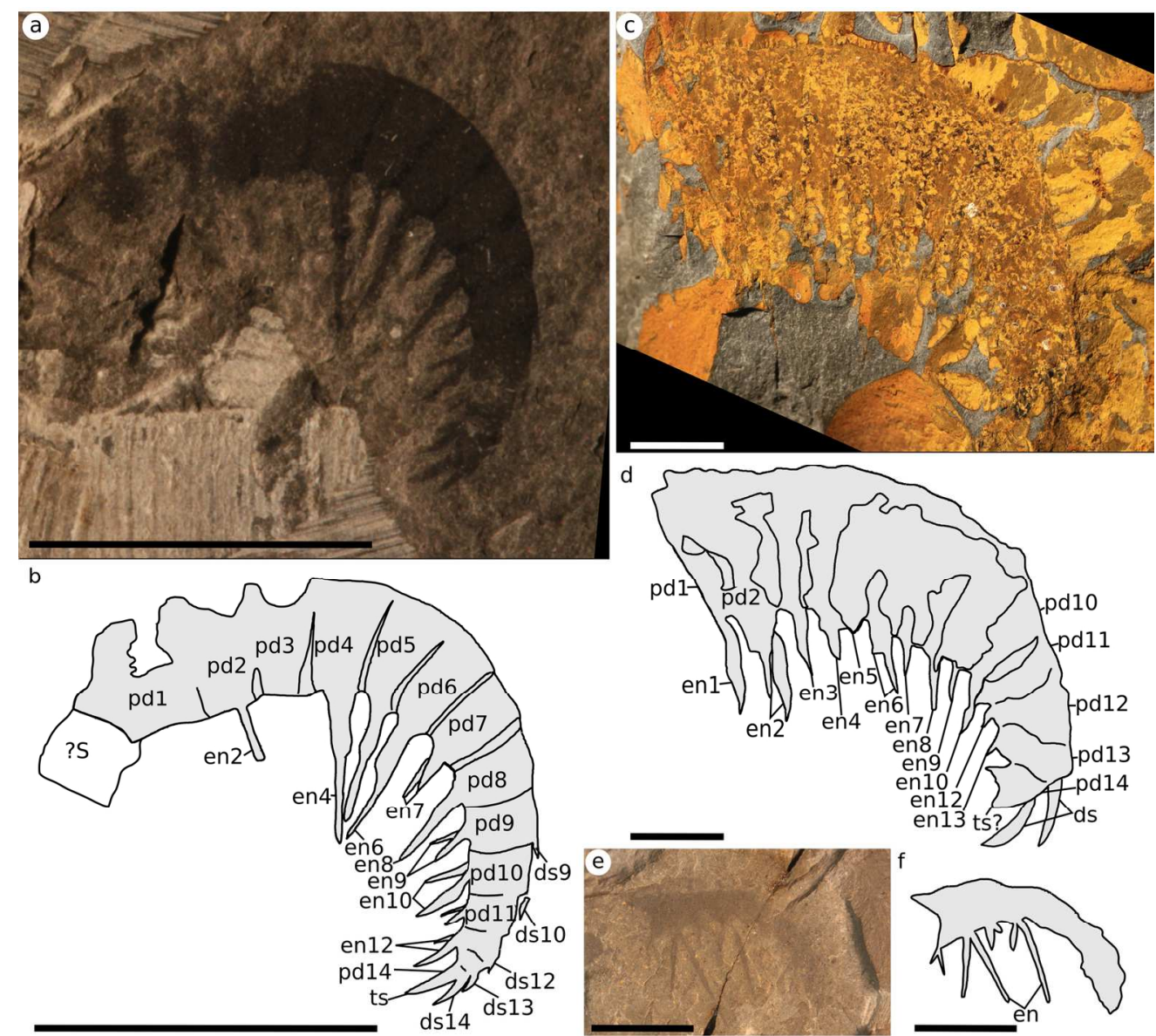

Figure 3. Anomalocaris pennsylvanica from the Kinzers Formation. (a,b) Holotype USNM 80487; (c,d) YPM 10425; (e,f) USNM 255611. Scale bars $10 \mathrm{~mm}$. Abbreviations: dsX, dorsal spine X; enX, ventral endite X; $\mathrm{pdX}$, podomere $\mathrm{X} ;$ ?S, putative shaft podomere; ts, terminal spine. 


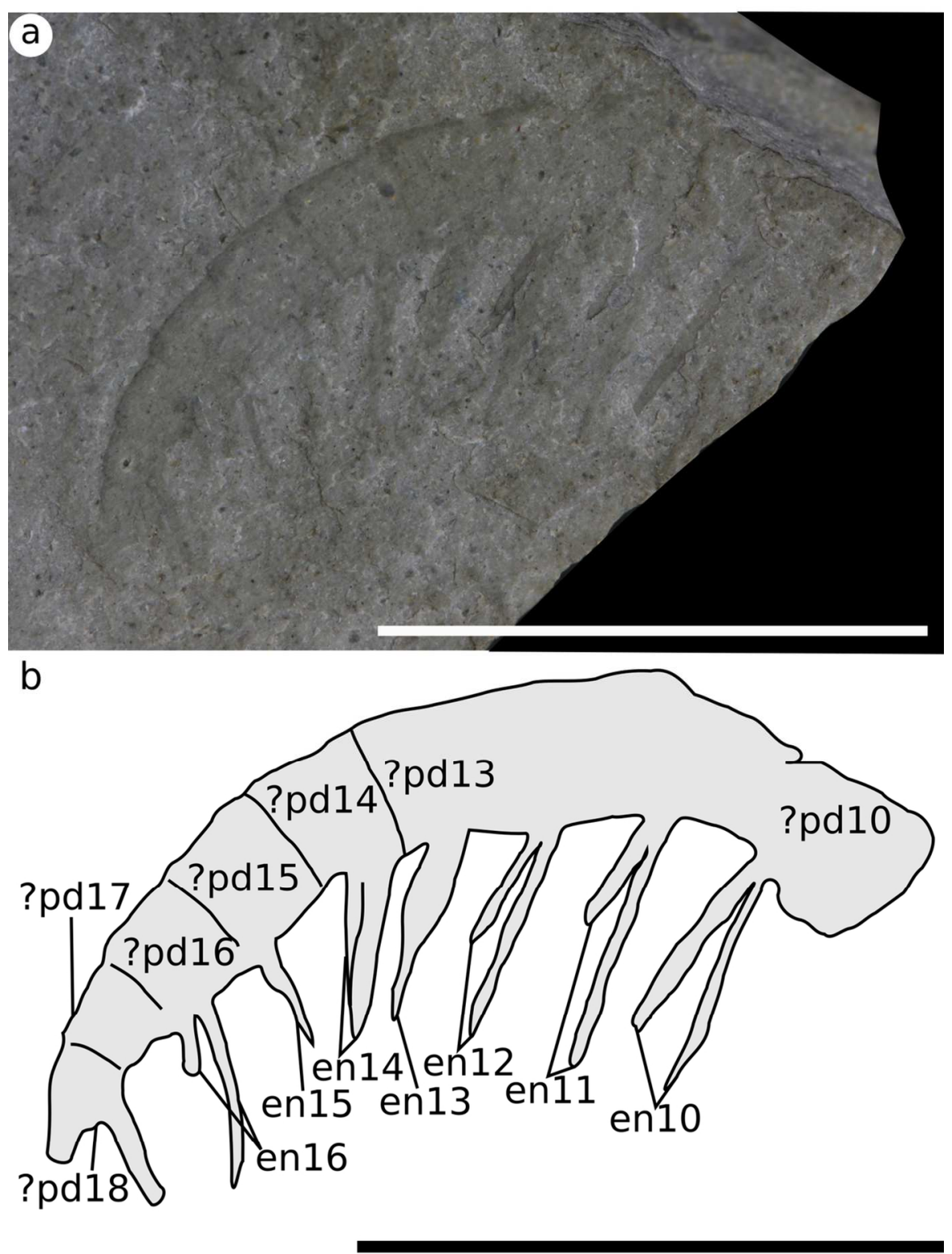

Figure 4. Tamisiocaris aff. borealis from the Kinzers Formation. (a,b) PA 388. Scale bars $10 \mathrm{~mm}$. Abbreviations: en, ventral endite; ?pdX, podomere $\mathrm{X}$, inferred from complete $\mathrm{T}$. borealis appendages.

$107 \times 145 \mathrm{~mm}(300 \times 300 \mathrm{DPI})$ 

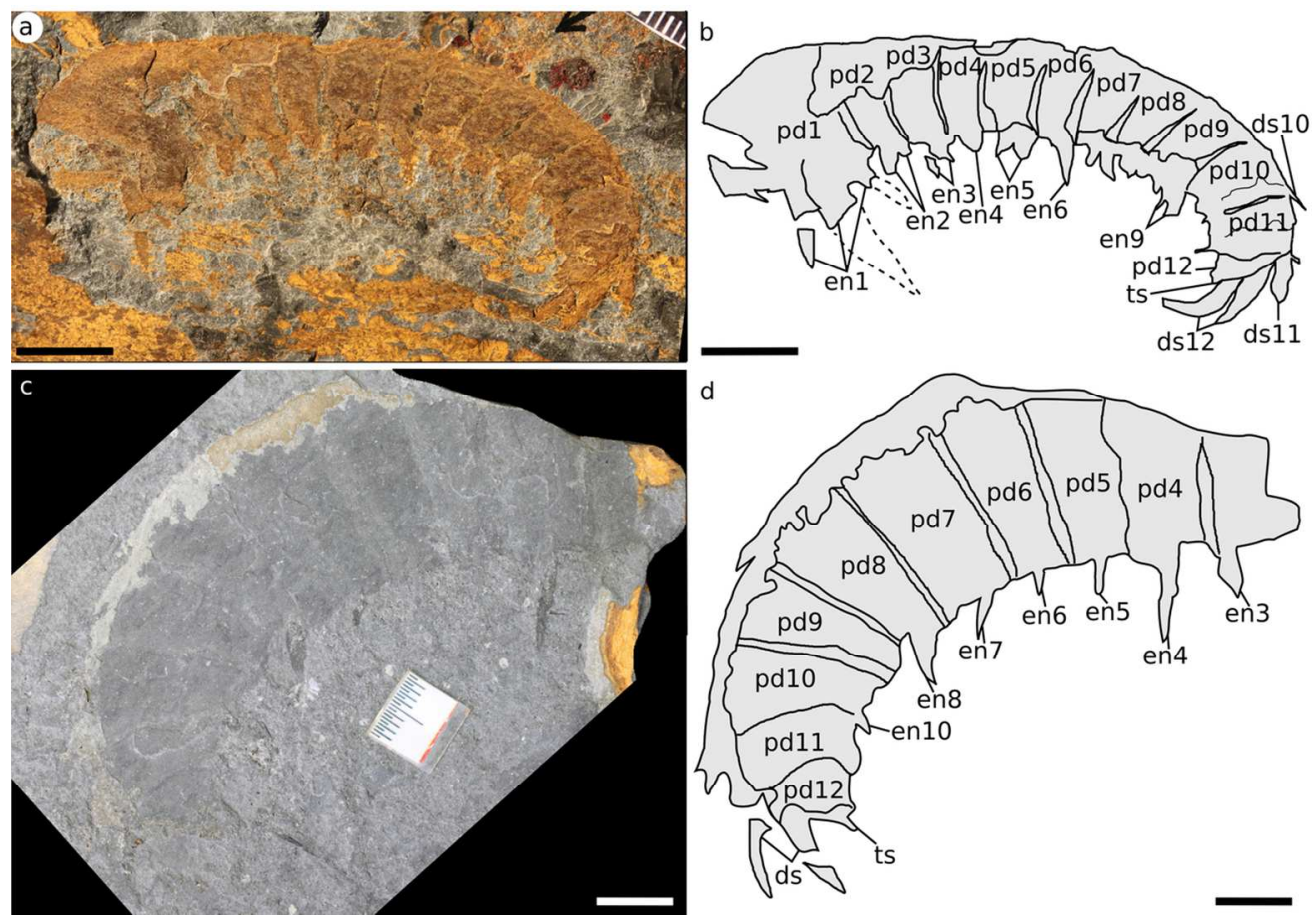

Figure 5. Amplectobelua aff. symbrachiata from the Kinzers Formation. (a,b) YPM 14388; (c,d) PA 390. Scale bars $10 \mathrm{~mm}$. Abbreviations: ds, dorsal spines; enX, ventral endite $X$; pdX, podomere $X$.

$117 \times 82 \mathrm{~mm}(300 \times 300 \mathrm{DPI})$ 
Figure 6. Reconstructions of Radiodonta from the Kinzers Formation, and other frontal appendages with similar morphology. (a) Anomalocaris pennsylvanica; (b) Anomalocaris canadensis; (c) Tamisiocaris aff. borealis; (d) Tamisiocaris borealis; (e) Anomalocaris briggsi; (f) Amplectobelua aff. symbrachiata; (g) Amplectobelua symbrachiata; (h) Amplectobelua stephenensis; (i) ?Laminacaris sp; (j) Laminacaris chimera. Dotted lines show parts of appendage that are not preserved. Line drawings (b), (g), and (h) adapted from Daley \& Budd (2010, text-fig. 1A, F, G), (d) adapted from Vinther et al. (2014, extended data fig. 6a), (e) adapted from Daley et al. (2013b, fig. 2), and (j) redrawn from Guo et al. (in press, fig. 3A).

$$
234 \times 326 \mathrm{~mm}(300 \times 300 \mathrm{DPI})
$$


Figure 7. Palaeogeographic reconstruction to $510 \mathrm{Ma}$ from GPlates (Scotese 2016). White star shows Kinzers Formation; black stars show other Stage 4 sites where radiodont fossils have been found. Abbreviations: $\mathrm{B}$, Balang Formation; Ca, Carrara Formation; Cr, Cranbrook Formation; E, Emu Bay Shale; K, Kinzers Formation; L, Latham Shale; P, Pioche Formation; V, Valdemiedes Formation; W, Wulongqing Formation. 